\title{
DEL CONSUMO DE BIENES MATERIALES A LA INTERACCIÓN TEXTO - LECTOR
}

Por

Giovanna Carvajal Barrios ${ }^{1}$

Profesora de la Escuela de Comunicación Social

Facultad de Artes Integradas

Universidad del Valle

giovanacarv@hotmail.com

\section{Resumen}

El artículo aborda la interacción texto-lector y sus relaciones con la apropiación de bienes materiales. En él se plantea que el consumo cultural constituye un ámbito donde se dan permanentes y particulares apropiaciones, y que a partir de las relaciones texto-lector y objeto-consumidor, se puede hablar de la cultura como un espacio destinado a las singularizaciones. El texto reconoce la relación dialéctica entre texto y lector, a partir de la cual se puede generar, o bien una coincidencia entre la interpretación del lector y las intenciones del autor, o una transgresión del esquema propuesto por este último, en virtud de la libre iniciativa del destinatario. Se reconoce entonces que la asimetría entre texto y lector puede desembocar en una preeminencia del propósito del autor o en una subversión de la construcción y la valoración estética por parte del lector.

\section{Palabras claves:}

Lectura, Interacción texto-lector, Consumo de objetos.

\footnotetext{
${ }^{1}$ Comunicadora Social, Licenciada en Música y Magíster en Comunicación y Diseño Cultural.
} 
En síntesis, lo que se propone desarrollar este artículo es que el consumo cultural constituye un ámbito donde se dan permanentes y particulares apropiaciones, y que a partir de las relaciones texto-lector y objeto-consumidor, podemos hablar de la cultura como un espacio destinado a las singularizaciones.

Tradicionalmente -desde una perspectiva puramente economicista- el consumo ha sido considerado como el punto de llegada del proceso productivo. Carlos Marx criticó esta visión, señalando que así como la producción es en sí misma un proceso de consumo, pues se consumen la fuerza de trabajo, la materia prima y los medios de producción, el acto de consumo es también un acto de producción. Esto lo planteaba no solamente porque los objetos consumidos contribuyen a la reproducción de la fuerza de trabajo o a la re-creación del cuerpo, sino porque es en el momento del consumo cuando el producto se realiza como tal.

Thorstein Veblen, por su parte, señalaba que los objetos consumidos se incorporan a la identidad personal y social del consumidor, lo cual ocurre en un marco social en el que se teje una red de obligaciones y contratos de tipo simbólico. Según él, en el consumo los objetos dejan de ser bienes neutrales y se convierten en atributos, insignias de identidades y en símbolos de las relaciones y obligaciones sociales ${ }^{1}$.

Lo que estos dos teóricos nos muestran es un cambio en el modo de abordar la temática del consumo, pues éste, para ellos, no se reduce al análisis del proceso de intercambio mercantil, sino que constituye un fenómeno social más amplio que merece ser estudiado en toda su complejidad.

Este artículo esboza una serie de relaciones entre los planteamientos de varios autores que han analizado el proceso de consumo, por un lado, y la interacción texto-lector, por otro, entendiendo esta última como la apropiación que un sujeto hace de los mensajes que le llegan a través de diferentes medios. Una vez construida la trama -que desde luego será sólo parcial- veremos cómo muchas de las acepciones teóricas hechas alrededor del consumo de bienes materiales pueden darnos pistas para el análisis del consumo de bienes simbólicos. Dicho de otro modo, estas dos formas de consumo tienen rasgos en común, en la medida en que forman parte de un mismo entramado cultural.

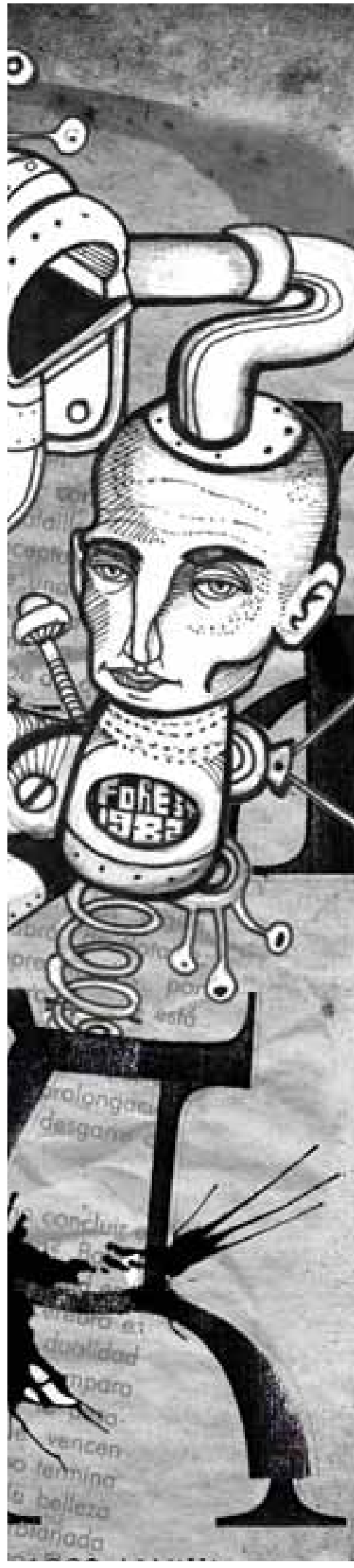


Mary Douglas y Baron Isherwood en su libro "El mundo de los bienes: hacia una antropología del consumo"2, plantean que es inconveniente asumir el consumo de mercancías única y exclusivamente como el objetivo del trabajo, pues independientemente del lugar que ocupan en el proceso de producción, los objetos actúan como mediadores en las relaciones entre los sujetos. Por lo tanto, si bien es cierto que el uso de las mercancías constituye el corazón de la vida económica de un grupo social, también lo es que representa un modo de aproximación a la forma de ser de una cultura. En el consumo se encuentra la historia vital del individuo y, por qué no, de una sociedad. Al respecto, Douglas e Isherwood afirman que las decisiones relativas al consumo constituyen la fuente vital de una determinada cultura: "la cultura evoluciona y la gente desempeña un importante papel en el cambio. El consumo es, por antonomasia, la arena en donde la cultura es motivo de disputas y remodelaciones" 3 . Las decisiones que tomemos con relación a él no sólo "expresan y generan lo que conocemos como cultura en el más general de los sentidos”, sino que además pueden determinar la evolución de la cultura misma ${ }^{4}$.

Otro de los aportes relevantes de estos dos autores se relaciona con la importancia del significado social de los objetos y su papel como otorgadores de sentido en una cultura. Con esto señalaban que, además de ser necesarios para la subsistencia y el despliegue competitivo, los objetos son la manera en que se hacen visibles y estables las categorías de una cultura. Pero veamos en qué sentido ellos afirman que las mercancías sirven para establecer y mantener las relaciones sociales.

El planteamiento surge de lo que ellos denominan la necesidad de establecer, por lo menos temporalmente, los significados públicos, ya que uno de los principales problemas de la vida en sociedad es que los significados están cambiando permanentemente. Entonces se hace necesario instaurar rituales que pongan freno a dicha tendencia y que se encarguen de dar estabilidad y un cierto grado de cohesión a los significados. Desde este punto de vista, los bienes son considerados como accesorios rituales de un acto ritual que es el consumo, y cuya finalidad "consiste en darle sentido al rudimentario flujo de los acontecimientos" ${ }^{\text {" }}$. Esto a su vez nos remite a una característica del hombre como ser racional: la necesidad de darle sentido al medio ambiente en que vive. De allí que "el objetivo más general del consumidor sólo puede ser construir un universo inteligible con las mercancías que elija ${ }^{6}$. Y más adelante afirmarán: "La elección de mercancías crea incesantemente ciertos momentos de discriminación, desplaza unos y refuerza otros. Los bienes son entonces la parte visible de una cultura. Están ordenados en panoramas y jerarquías que ponen en juego toda la escala de discriminaciones de la que es capaz la especie humana ${ }^{7}$. 
Definir el consumo como una actividad ritual significa, a su vez, considerar las mercancías como portadoras de sentido. Con ellas los individuos ponen de manifiesto sus juicios particulares, se confrontan permanentemente con sus semejantes y expresan algo sobre sí mismos. Pero al mismo tiempo que las categorías sociales se hacen visibles, son redefinidas constantemente. Esta transformación de las categorías se produce cuando un individuo tiene la oportunidad de asistir -lo cual se convierte casi en requisito- a los rituales de consumo de otras personas y de poner en circulación sus propios juicios con relación a los objetos empleados en la celebración de diferentes acontecimientos.

En resumen los bienes materiales no sólo son portadores de significados de acuerdo con la apropiación que se haga de ellos, sino que constituyen una manera de clasificación y de relación entre los individuos. Así, como lo afirmaran Douglas y Isherwood, "lo más probable es que la oportunidad de un hombre para no resultar innecesario durante la década siguiente, y ciertamente la habilidad para guiar a sus hijos hacia la corriente principal de la sociedad, dependan de la escuela de consumo que mantiene ${ }^{8}$.

Con los elementos esbozados en el numeral anterior es posible abordar una primera relación entre el consumo de objetos y la interacción texto-lector; pero antes es necesario retomar una de las afirmaciones más relevantes dentro de los capítulos del texto de Douglas y Isherwood al que se ha venido haciendo referencia: "Si se ha dicho que la función esencial del lenguaje es su capacidad para la poesía, asumiremos que la función esencial del consumo es su capacidad para dar sentido [...] Olvidémonos de que las mercancías sirven para comer, vestirse y protegerse. Olvidemos su utilidad e intentemos en cambio adoptar la idea de que las mercancías sirven para pensar; aprendamos a tratarlas como un medio no verbal de la facultad creativa del género humano?

Porque más allá de la necesidad que tenemos de comer, de vestimos, de tener un sitio dónde vivir, está nuestro interés en que la comida, el vestido y la vivienda que nos pertenecen lleven el sello de quienes somos y lo que pensamos; la huella de la manera como vemos y vivimos el mundo.

En este punto, resulta pertinente retomar brevemente una formulación de Pierre Bourdieu. Partiendo de los planteamientos de Emile Durkheim y Marcel Mauss, Bourdieu afirma que existe una correspondencia entre estructura social y estructuras mentales, entre las divisiones objetivas del mundo social y los principios de visión y clasificación que los agentes sociales le aplican al mundo. Ahora bien, siendo el sistema escolar una de las instituciones encargadas de sentar las bases para esa clasificación o jerarquización social, los agentes sociales interiorizan dicha jerarquía y actúan en correspondencia con ella. De esta forma, las estructuras mentales de los individuos y las formas de clasificación que ellos asimilan, cumplen una función política particular: ejercer un mecanismo de dominación y lograr la integración social cuya base es un orden arbitrario. 
En un análisis aplicado a la sociedad francesa de la década de 1970, Bourdieu ${ }^{10}$ señala que mientras en las capas bajas de la población la función predominante de los objetos tiene que ver con su utilidad práctica, en las clases altas ésta se relaciona con sus características estéticas. Sin embargo, en un país como Colombia lo utilitario y lo estético se entrecruzan de diversas maneras. Vemos entonces que la necesidad de hacer bello y agradable el entorno es un criterio que tiene mucho peso a la hora de decorar la casa o de adquirir un objeto. De hecho, el planteamiento de Bourdieu en cuanto a que el gusto no es una cosa etérea o gaseosa, sino que nos habla de las relaciones sociales es, sin lugar a dudas, clave en cualquier análisis de consumo. No obstante, también es importante tener en cuenta que, por determinante que sea el lugar que un individuo ocupa en la estructura social, existen actitudes y comportamientos que obedecen a causas múltiples y a razones muy complejas.

Es necesario reconocer que este paso veloz por un autor de tanta trascendencia, puede conducir a un esquematismo exagerado. De todas maneras, en un tema como el que se desarrolla aquí, el análisis conduce por diversos caminos, algunos de los cuales pugnan por no dejarse atrapar en determinismos absolutos como en ocasiones podrían sugerir algunas de las formulaciones de Bourdieu.

Cerrando este paréntesis, me referiré a algunas ideas desarrolladas por Umberto Eco en su libro "Lector in Fabula" punto de partida, veamos lo que expresa en la siguiente cita: “Todo símbolo es una cosa viva, en un sentido real que no es una mera figura retórica. El cuerpo de los símbolos cambia lentamente, pero su significado crece de modo inexorable, incorpora nuevos elementos y suprime los viejos" ${ }^{\prime 2}$.

Ese mismo dinamismo que se da en el terreno de la significación lingüística, equivale en cierta forma a lo que planteaban Douglas e Isherwood con relación a las mercancías. Ambos anotaban que el valor otorgado a ellas es un valor acordado entre muchos consumidores que al estar asociados determinan la mayor o menor importancia de los acontecimientos, bien sea manteniendo antiguos juicios o revocándolos. Por otro lado, afirmaban que el consumo, no obstante ser considerado como una actividad ritual, constituye un proceso activo en el cual todas las categorías sociales son permanentemente redefinidas. El tipo de valores que entran en juego, la escala de discriminaciones que se reproduce pero que también se transforma, los criterios con base en los cuales se determina si un objeto es susceptible o no de ser convertido en mercancía, nos hablan justamente de un grado de movilidad, de una vitalidad que está en la base del proceso de consumo.

El planteamiento de Eco se relaciona también con algo que Igor Kopytoff desarrolla en su texto "La biografía cultural de las cosas" ${ }^{13}$. Dice KopytofI que los objetos, así como las personas, tienen una biografía y que por lo tanto pueden ser analizados diacrónicamente, pues las cosas y los valores que a ellas se les asignan, se transforman con el tiempo. Pero así mismo, es posible mirar esa biografía desde un punto de vista sincrónico y darnos cuenta de que algo considerado mercancía por una persona o por un grupo, puede no serlo para otros, en un mismo momento y en una misma sociedad. Afirma además que "estos cambios y diferencias en materia de cuándo y cómo una cosa se convierte en mercancía, revelan la 'economía moral' que está detrás de la economía objetiva de las transacciones visibles ${ }^{14}$.

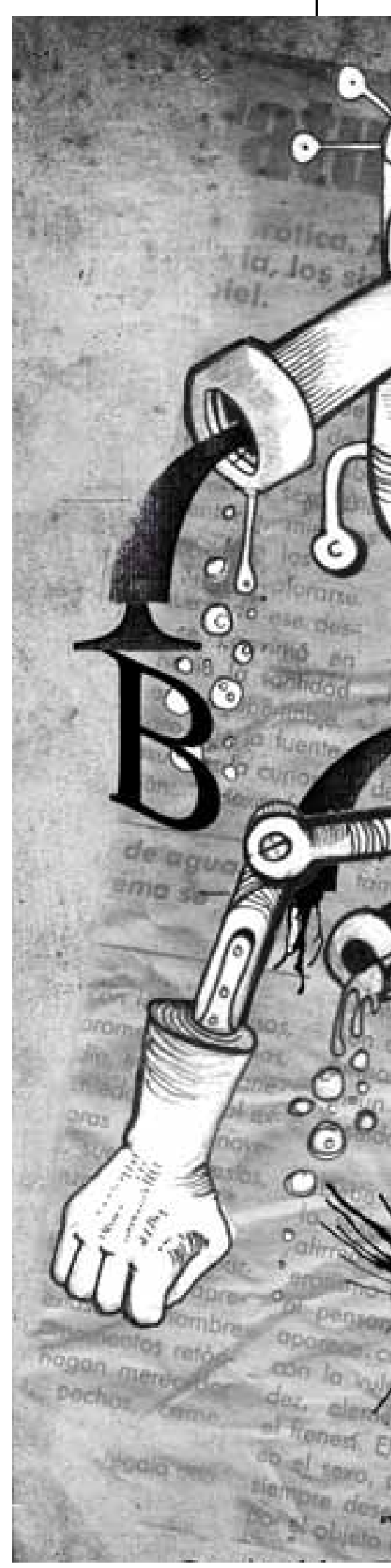




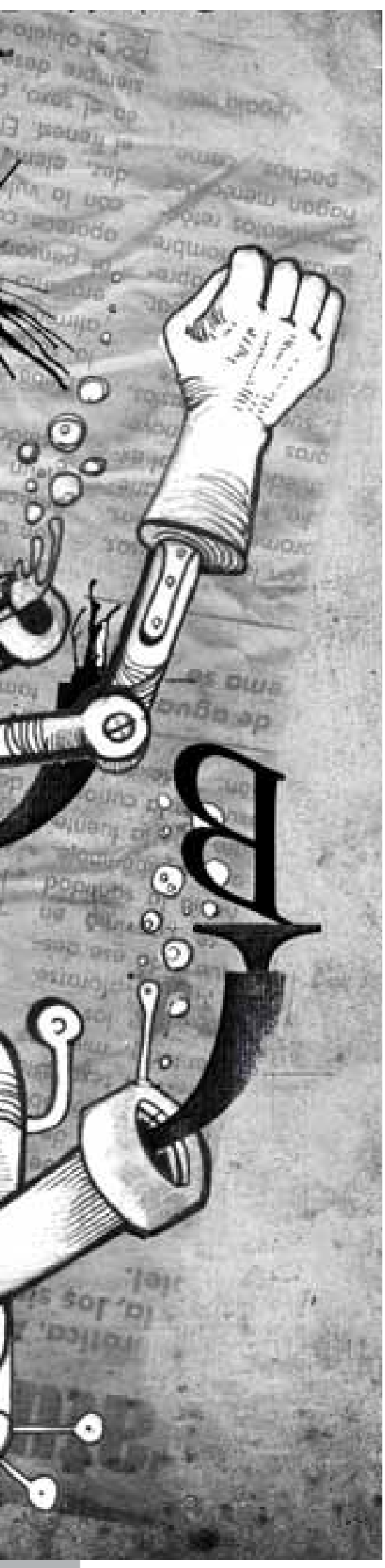

Por otra parte, Umberto Eco expone un planteamiento interesante cuando se refiere a la dialéctica en el pensamiento de Pierce: “...el interpretante final no es final en un sentido cronológico. La semiosis ${ }^{15}$ muere permanentemente, pero, así como muere, también renace en sus propias cenizas ${ }^{16}[\ldots]$ Puede decirse que el círculo de la semiosis se cierra permanentemente, y también, que no se cierra nunca. El sistema de los sistemas semióticos, que podría parecer un universo cultural separado (como pretende el idealismo) de la realidad, lleva, de hecho, a actuar sobre el mundo y a modificarlo; pero cada acción modificadora se convierte, a su vez, en un signo y genera un nuevo proceso semiósico"17.

Este fragmento nos lleva a pensar en la producción de sentido que contiene el acto del consumo. Porque a través de los objetos no sólo nos decimos algo de nosotros mismos, sino que lo comunicamos a los demás. Se trata de un reconocimiento tanto interior como exterior, de una dinámica entre lo subjetivo y lo objetivo que se colman y se transforman mutuamente. En otras palabras, y siguiendo aquí a Kopytoff, el modo en que empleamos los objetos, las relaciones que establecemos con ellos, constituyen formas de comunicación.

Siempre que nos relacionamos con los bienes simbólicos estamos expresando nuestra capacidad participativa y creativa en la reconstrucción de dichos bienes. Así mismo, como lo afirma Kopytoff, es en el proceso de apropiación donde las cosas adquieren su valor, pues en últimas, apropiarse de un bien material implica también cargarlo de sentido: ¿Qué representa para mí ese objeto? ¿Por qué me apropio de él en tal o cual circunstancia? ¿Con qué fin? ¿Por qué ese objeto y no otro? Sostiene este autor que "desde el punto de vista cultural la producción de mercancías es también un proceso cultural y cognoscitivo: las mercancías no sólo deben producirse materialmente como cosas, sino que también deben estar marcadas culturalmente como un tipo particular de $\operatorname{cosas"18}$.

Aunque sabemos que forma parte del proceso de intercambio, el consumo, desde esta perspectiva, es un acto que trasciende dicha instancia. Como lo manifiesta el mismo Kopytoff, aunque todo proceso de intercambio tienda a la mercantilización, el movimiento básico de la cultura es el de singularizar, es decir, que la cultura es la única capaz de liberar de su estatus mercantil a los bienes. 
Este apartado se ocupará específicamente de la relación texto-lector, haciendo un paralelo entre las formulaciones de Umberto Eco y Wolfgang Iser, quienes han hecho aportes significativos en este ámbito.

El punto de partida de Eco consiste en plantear la cooperación textual como una actividad promovida por el texto y en tratar de definir a partir de qué estrategias textuales pueden convivir en una obra el estímulo a la libre intervención interpretativa y al mismo tiempo un control de las participaciones del lector ${ }^{20}$. Iser, por su parte, propone la relación entre texto y lector como una dinámica de interacción que, si bien no posee cier tos rasgos de la comunicación cara a cara, puede ser considerada como un proceso de intercambio cuyas principales características son la transformación mutua, la presencia de componentes contingentes y la existencia de espacios de indeterminación que deben ser completados por el lector.

La elaboración de Eco se ubica en el marco de la pragmática del texto, la cual aborda "la actividad cooperativa en virtud de la cual el destinatario extrae del texto lo que el texto no dice (sino que presupone, promete, entraña e implica lógicamente), llena espacios vacíos, conecta lo que aparece en el texto con el tejido de la intertextualidad de donde este texto ha surgido y donde habrá de volcarse" ${ }^{21}$.

Se trata, como lo expresa Iser citando a Virginia Wolf, de una dialéctica entre lo que se dice y lo que se calla, de una incitación al lector para que llene los espacios vacíos, iniciando de esta forma la actividad constitutiva del texto y por ende, la interacción entre texto y lector. Iser se interesa por desarrollar aún más esa noción y para tal fin hace un análisis detallado de lo que Roman Ingarden denomina espacios de indeterminación.

Ninguno de los dos ve al lector como un sujeto ajeno al proceso de elaboración del texto. Por el contrario, lo consideran principio activo de la interpretación y pieza fundamental del marco generativo del propio texto. Su misión consiste en actualizar la 'cadena de artificios expresivos' que el texto contiene pues los espacios que quedaron en blanco fueron dejados por el autor, como parte de su estrategia textual para que los llenara el destinatario.

Sin embargo, para que este proceso dé lugar a una interpretación aproximada a la que el autor tenía en mente al momento de producir el texto, es necesario ejercer un control sobre la iniciativa del destinatario. Dicho control consiste, por un lado, en tener una imagen del sujeto al cual va dirigido el texto, es decir, hacer una selección entre los receptores potenciales y definir a cuál o a cuáles de ellos interpelará. Por otro lado, se trata de diseñar una estrategia que permita a ese sujeto encontrar el camino por el cual llegar a la propuesta interpretativa del enunciador. 
Veamos cómo es desarrollado esto por Iser. Él plantea que cuando nos relacionamos con alguien, tendemos a actuar con base en la percepción que el otro, o los otros, tienen de nosotros. Pero como nos resulta imposible conocer a ciencia cierta cuál es esa percepción y cómo asumen nuestros interlocutores la relación que establecen con nosotros, nos vemos en la necesidad de llenar ese vacío de experiencia, y actuamos como si supiéramos de qué modo somos experimentados por los otros. En el texto escrito se hace necesario que el autor no sólo imagine un modelo de destinatario, sino que proyecte en el texto una imagen de sí mismo como enunciador ${ }^{22}$.

En cuanto a lo que Eco denomina la 'estrategia textual', la cual ha de permitir un recorrido interpretativo acorde con las intenciones del autor (y con un mayor o menor grado de libertad según esas mismas intenciones), Iser plantea (otra vez siguiendo a Ingarden) la necesidad de ejercer un control sobre los espacios de indeterminación que si bien pueden constituir una de las riquezas del texto, representan un riesgo para la finalidad que éste persigue. Lo que hace el lector frente a esos espacios es, precisamente, determinarlos para así lograr la concreción de la obra. Y en ese juego de determinaciones posibles, de disonancias múltiples, de contrastes variables, es donde se hace posible la configuración del objeto intencional de la obra. En otras palabras, los espacios de indeterminación sirven para destacar la finalidad del texto al contrastarla con las diferentes opciones interpretativas tomadas por los destinatarios.

La posibilidad de que un texto sea interpretado por el camino correcto, desde el punto de vista del autor, depende de si éste diseña una estrategia que tenga en cuenta los posibles movimientos que realice el lector, previendo incluso lo que Iser denomina los 'componentes contingentes' propios de toda interacción. Pero además, como lo expresa Eco, el autor del texto debe organizar su estrategia con base en una serie de competencias a partir de las cuales el lector puede dar contenido a las expresiones que el primero utiliza. Por lo tanto, el 'lector modelo' es aquel que, siendo previsto por el autor, sea capaz de cooperar en la actualización textual tal y como él lo había planeado y de "moverse interpretativamente igual que él se ha movido generativamente" ${ }^{23}$.

Sin embargo, como lo expresan ambos autores, en la relación texto-lector no podemos hablar de interpretaciones legítimas o ilegítimas, correctas o incorrectas, sino de un mayor o menor grado de correspondencia con el objeto intencional de la obra: "En la concreción mediante la constitución del sentido surge la determinación de la obra. Hay que preguntarse si esta determinación no es más bien de carácter individual propia del lector, y menos una que se encuentre sometida a la referencia de lo verdadero o falso" ${ }^{24}$. 
De todos modos, es importante anotar que aún cuando la interpretación hecha por el lector coincida con el propósito estético y comunicativo del autor, nunca habrá una total correspondencia entre lo uno y lo otro. Como lectores o como espectadores, podemos cooperar en la constitución de un texto narrativo y captar lo que supuestamente el autor quería que sus destinatarios captaran. Sin embrago, nuestra participación síquica o afectiva en el relato ${ }^{25}$ es en alto grado subjetiva. Me atrevo a sugerir (sugerencia que, por lo demás, no tiene nada de novedoso) dos niveles de participación sin los cuales un texto carecería totalmente de sentido: Por un lado, la actividad cooperativa en la determinación, concreción o actualización del texto, y por otro, la participación afectiva, es decir, los procesos de proyección identificación que estando en el corazón de la vida, se ponen en movimiento a partir de la interacción texto-lector.

De hecho, se trata de dos niveles que en la práctica no se pueden separar, pero, que para efectos del análisis puede ser útil tener en cuenta. Ambos niveles remiten a su vez a dos ámbitos de la investigación: por un lado, el ámbito de la producción de los discursos, pues para cualquier autor es indispensable comprender de qué manera se produce la interacción texto-lector para así poder diseñar estrategias textuales que le resulten eficaces. Por otro lado, remite al ámbito del consumo y la apropiación de bienes simbólicos pues para cualquier investigador que se interese por este campo es fundamental realizar un trabajo analítico sobre la participación del lector en la configuración del texto y confrontar, por medio de un trabajo empírico, lo que hasta el momento es un campo en ciernes.

Sin lugar a dudas, este ha sido un recorrido rápido y esquemático por las formulaciones de los teóricos citados. No obstante, quisiera hacer una corta anotación final que me parece importante. A partir del concepto de concreción o de actualización de los textos, podemos ver que existe una relación dialéctica entre texto y lector, a partir de la cual se puede generar, o bien una coincidencia entre la interpretación del lector y las intenciones del autor, o una transgresión del esquema propuesto por este último, en virtud de la libre iniciativa del destinatario. Así, la asimetría entre texto y lector puede desembocar en una preeminencia del propósito del autor o en una subversión de la construcción y la valoración estética por parte del lector. De todas maneras, nunca el texto producido va a ser idéntico al texto leído; pero además, lo cual es de indudable importancia, nosotros tampoco seremos los mismos después de leer un texto: algo de nosotros ha quedado en él. Algo de él ha quedado, irremediablemente, en nosotros. 


\section{Notas}

${ }^{1}$ Este planteamiento es desarrollado por Veblen en Teoría de la Clase Ociosa, México, Fondo de Cultura Económica, 1974.

2 DOUGLAS, Mary, ISHERWOOD, Baron. El mundo de los bienes: hacia una antropología del consumo, Grijalbo, México, 1986.

3 Ibid., p. 72.

4 Ídem.

5 Ibid, p. 80.

6 Ibid., p. 81.

7 Ídem.

8 Ibid., p. 108.

9 Ibid., p. 77.

${ }^{10}$ La distinción: Criterios y bases sociales del gusto, Taurus, Madrid, 1991.

${ }^{11}$ ECO, Umberto, Lector in Fabula, Editorial Lumen, Barcelona, 1981.

12 Ibid., p.51.

${ }^{13}$ KOPYTOFF, Igor, La vida social de las cosas, Grijalbo, México, 1986.

${ }^{14}$ Ibid., p. 89.

15 Peirce define el interpretante como "la idea que el signo origina en la mente del intérprete". Para ampliar este concepto, ver Eco,U, Lector in Fabula. p. 42-43.

16 Eco, Umberto, op. cit., p. 67.

1710 Ibid, p. 68.

18 KOPYTOFF, Igor, La vida social de las cosas, op. cit. , p. 89.

19 Ibid, p. 96.

20 Me estoy refiriendo nuevamente a Lector in Fábula, de manera particular a la introducción y a los tres primeros capítulos.

21 ECO, Umberto, Lector in Fábula, op. cit., p. 13.

22 La definición que empleo de "enunciador" y "destinatario" es tomada del texto de Alejandro Ulloa "La enunciación, el enunciador y el destinatario, Material didáctico del curso Escritura I, para uso exclusivo de la Universidad del Valle. El destinatario es definido por Ulloa como "una figura imaginaria del receptor real, presente en el lenguaje y marcada en el discurso", mientras que el enunciador es para él "una elaboración verbal que presenta de modo imaginario al emisor real; es su imagen proyectada en el discurso".

${ }^{23} 14$ ECO, Umberto, Lector in Fábula, op cit., p. 80.

24 SER, Wolfang, El Acto de Leer, Taurus, Madrid, 1987, p. 266

25 El concepto de participación afectiva es desarrollado por Edgar Morin en "El cine o el hombre imaginario”, Seix Barral, Barcelona, 1961, capítulo IV.

\section{Referencias}

Bourdieu, Pierre (1991) La distinción: Criterios y bases sociales del gusto. Madrid: Taurus.

Douglas, Mary \& Isherwood, Baron (1986) El mundo de los bienes: hacia una antropología del consumo. México: Grijalbo.

Eco, Umberto (1981) Lector in Fabula. Barcelona: Editorial Lumen.

Iser, Wolfgang (1987) El Acto de Leer. Madrid: Taurus.

Kopytoff, Igor (1986) La vida social de las cosas. México: Grijalbo.

Morin, Edgar (1961) El cine o el hombre imaginario. Barcelona: Seix Barral.

Ulloa, Alejandro (s.f) "La enunciación, el enunciador y el destinatario". Material didáctico del curso Escritura I, para uso exclusivo de la Universidad del Valle.

Veblen, Thorstein (1974) Teoría de la Clase Ociosa. México: FCE. 